Western University

Scholarship@Western

$6-9-2020$

\title{
Association Between Changes in Subjective and Objective Measures of Mobility in People With Lower Limb Amputations After Inpatient Rehabilitation
}

Gabrielle Cieslak

Humberto Omana

Edward Madou

Courtney Frengopoulos

Ricardo Viana

See next page for additional authors

Follow this and additional works at: https://ir.lib.uwo.ca/ptpub

Part of the Physical Therapy Commons 
Authors

Gabrielle Cieslak, Humberto Omana, Edward Madou, Courtney Frengopoulos, Ricardo Viana, Michael W Payne, and Susan W. Hunter 
Association between changes in subjective and objective measures of mobility in people with lower limb amputations after inpatient rehabilitation

Gabrielle Cieslak, ${ }^{1}$ Humberto Omana MSc, ${ }^{1}$ Edward Madou MSc, ${ }^{1}$ Courtney Frengopoulos MSc, ${ }^{1}$ Ricardo Viana OT MD, ${ }^{2,3}$ Michael W. Payne MSc MD, ${ }^{2,3}$ Susan W. Hunter PT PhD,,${ }^{1,3,4}$

1. Faculty of Health Sciences, University of Western Ontario, London, Ontario, Canada;

2. Department of Physical Medicine \& Rehabilitation, Parkwood Institute, London, Ontario, Canada;

3. Department of Physical Medicine \& Rehabilitation, Schulich School of Medicine \& Dentistry, University of Western Ontario, London, Ontario, Canada;

4. School of Physical Therapy, University of Western Ontario, London, Ontario, Canada.

\section{Corresponding Author:}

Dr. Susan W. Hunter

University of Western Ontario

School of Physical Therapy

Room 1588, Elborn College

London, ON, Canada, N6G 1H1

Email: susan.hunter@uwo.ca 
Author Disclosures: The authors declare no conflicts of interest. A preliminary version of the present study was presented as a poster at the $67^{\text {th }}$ Annual Canadian Association of Physical Medicine \& Rehabilitation (CAPM\&R) Scientific Meeting. This work was supported by the St. Joseph's Healthcare Foundation Cognitive Vitality and Brain Health Seed Funding Opportunity in London, Ontario, Canada. 


\title{
Association between changes in subjective and objective measures of mobility in people with lower limb amputations after inpatient rehabilitation
}

\begin{abstract}
Functional recovery for people with lower limb amputations (PLLA) is quantified using objective or subjective measures of performance. In this brief report, the prospective relationship between objective and subjective mobility after rehabilitation was evaluated in PLLA. Adults undergoing inpatient prosthetic rehabilitation for a first unilateral transtibial or transfemoral level lower limb amputation were recruited. Assessment times: discharge and 4-months follow-up. Gait velocity and the L Test under single-task (ST) and dual-task (DT) conditions measured objective mobility. The Prosthetic Evaluation Questionnaire (PEQ, Section 4 and question 5b) measured subjective mobility. Paired t-tests and Pearson correlation analysis evaluated change over time and the association between mobility types, respectively. Twenty-one PLLA (61.6 \pm 8.2 years) participated. Gait velocity significantly improved (ST and DT: p<0.001). L Test significantly improved for single- $(\mathrm{p}=0.002)$, but not dual-task conditions. No statistically significant PEQ changes were observed. One subjective mobility question (sidewalk walking) correlated with objective mobility at follow-up (L Test-ST and DT: r=-0.77, p<0.001). Objective mobility improved after discharge; however, subjective reporting had no change. Lack of association may represent a mismatch between quantitative outcomes and subjective selfassessment. Both subjective and objective measures of mobility should be collected to provide a holistic picture of clinical and patient-relevant outcomes in PLLA.

Keywords: Gait, Prosthesis and Implants, Lower Extremity, Self-assessment
\end{abstract}




\section{BACKGROUND}

People with a lower limb amputation (PLLA) undergo intensive rehabilitation to achieve safe walking using a prosthesis. For many, rehabilitation involves inpatient stay and prolonged periods of therapy in order to learn the use of a prosthesis, gain walking independence and the ability to complete activities of daily living. ${ }^{1}$ Importantly, adequate walking is associated with higher social functioning ${ }^{2}$ and is the most important factor influencing quality of life in PLLA. ${ }^{3}$ Therefore, the examination of walking abilities is a critical component of mobility assessments in this population.

Currently, objective clinical measures of mobility (e.g., performance-based walking tasks) are considered the gold standard for clinicians to examine rehabilitation progress and to prognosticate future success. ${ }^{4}$ Most walking tests assess ambulation in isolation. However, walking and activities of daily life often require the ability to complete multiple tasks simultaneously ${ }^{5}$. Dual-task gait testing, performing a secondary task while walking, is believed to approximate real-world walking abilities. ${ }^{6}$ The interpretation of both single-and dual-task objective mobility tests can assist clinicians to understand an individual's functional abilities. ${ }^{7}$ However, objective mobility tests in controlled environments may not accurately reflect PLLA's perception of their own ability to move within their community. For instance, clinical settings include bright lighting and exemplar conditions (e.g., dry floors, no obstacles), yet real-life involves complex environments (e.g., walking outside).

There is a growing awareness of the importance of subjective aspects of rehabilitation in PLLA. ${ }^{8-11}$ Subjective mobility assessments usually entail questionnaires in which individuals rate their ability to complete a task. Subjective mobility tests are useful as they allow for the assessment of perceived mobility in scenarios difficult or impossible to test in clinical settings. 
Subjective tests tailored to specific patient populations offer a patient-centered view of ability and relevant outcomes.

The relationship between subjective and objective measures of mobility has previously been examined in stroke patients. ${ }^{12}$ Interestingly, although people after a stroke regained mobility, they did not perceive their function as improved. ${ }^{12}$ An evaluation of the relationship between measured and perceived changes in walking ability following inpatient rehabilitation in PLLA has not been done. It is essential to establish this relationship in order to provide a holistic picture of rehabilitation in PLLA.

The study objectives were: (1) to evaluate subjective and objective mobility change between discharge and 4-months after inpatient rehabilitation in PLLA, and (2) to evaluate the relationship between subjective and objective mobility at discharge and the 4-months follow-up. Our study hypothesized that both mobility types would improve after discharge. A strong correlation between better objective performance (i.e., faster walking) and better subjective reports (i.e., higher perceived walking abilities) was also expected.

\section{METHODS}

\section{Design and study population}

This was a prospective cohort study of consecutive admissions of individuals undergoing inpatient prosthetic rehabilitation for a first unilateral transtibial or transfemoral level lower limb amputation at Parkwood Institute in London, Ontario (April 2016-September 2017). Assessments took place at inpatient discharge and at a 4-months follow-up outpatient clinic appointment. The study was approved by the Health Sciences Research Ethics Board at the University of Western Ontario and by the Clinical Resources Impact Committee of the Lawson Health Research Institute. Written informed consent was obtained from all participants. This study was designed 
to adhere to the Strengthening the Reporting of Observational Studies in Epidemiology (STROBE) Statement ${ }^{13}$ (see Supplementary Checklist for details).

Individuals were eligible to participate if they were 50 years or older, spoke English, had a unilateral transtibial or transfemoral amputation and could walk 10 meters without the assistance of another person- mobility aid use was allowed. Exclusion criteria were any neurological or physical issues other than the amputation that limited movement with a prosthesis as assessed by the program physiatrist.

Self-reported demographic and medical history information included age, sex, height and weight to calculate body mass index, level of amputation, a self-reported fit of prosthesis rating as per the Prosthesis Evaluation Questionnaire (question 1B) with higher values indicating an "Excellent" fit, amputation etiology, type of comorbidities, number of medications, balance confidence measured using the Activities-specific Balance Confidence scale, ${ }^{14}$ and global cognitive status measured using the Montreal Cognitive Assessment ${ }^{15}$.

\section{Study Protocol}

\section{Objective mobility}

Gait velocity $(\mathrm{cm} / \mathrm{s})$ was recorded using the GAITRite ${ }^{\circledR}$ instrumented walkway $(6 \times 0.64$ m, CIR System Inc., Franklin, NJ, USA). One-meter distances before and after the walkway boundaries were used to account for acceleration and deceleration.

Functional mobility was assessed using the L Test of Functional Mobility (L Test). ${ }^{16}$ The L Test was developed for PLLA and examines the minimal amount of mobility needed for independent living. Using standard instructions, participants began sitting on an armless chair (height: $0.46 \mathrm{~m}$ ), and upon the word "go" rose to standing and walked three meters, turned $90^{\circ}$, 
walked seven meters, turned $180^{\circ}$, and walked the same path to return to a seated position. Performance was recorded to the nearest $100^{\text {th }}$ of a second using a stopwatch.

\section{Dual-task testing}

Single-task and dual-task trials were performed for each walking condition using standardized instructions. Each participant completed one trial of each condition. Participants were instructed to walk at a comfortable, everyday pace. Dual-task testing required participants to perform serial subtractions by threes from a random number between 100-150 while walking. No instructions on task prioritization were given. L Test dual-task testing is valid and reliable in PLLA. $^{7}$

\section{Subjective mobility}

Participants completed the Prosthesis Evaluation Questionnaire (PEQ $)^{17}$, a measure of quality of life designed for PLLA. The PEQ has 9 sections and 82 questions in total. Thirteen questions related to perceived walking ability were selected to assess subjective mobility (Group 4). One question from Group 5 assessed overall walking satisfaction. Participants reported their level of agreement to a statement by marking a $100 \mathrm{~mm}$ visual analog scale. Item scores are measured as the length from the left anchor to the participant's mark and a higher value (toward the right) corresponds to greater agreement with the question. The PEQ is valid and reliable in PLLA. ${ }^{17}$

\section{Statistical Analysis}

An a priori sample size calculation $(\alpha=0.05, \beta=0.20)$ determined that a minimum of 15 participants would be required based on an expected $15 \%{ }^{18}$ change in dual-task walking performance post-inpatient rehabilitation. A total of 30 participants were recruited to accommodate for a $20 \%$ drop out rate. Normality for continuous data was assessed for using 
Shapiro-Wilks tests, histograms and Q-Q plots. Participant demographic, clinical characteristics, and subjective and objective mobility performance were summarized using means and standard deviations or frequencies and percentages, as appropriate.

For objective \#1, the change between discharge and the 4-months follow-up for subjective and objective mobility performance were examined using paired t-tests. For objective \#2, a Pearson product moment correlation analysis was used to determine the association between objective and subjective measures of mobility at discharge and the 4-months follow-up. All analyses were done using SPSS, version 25.0 (IBM Inc., Chicago, IL, USA). Criteria for statistical significance was $p<0.003$ once adjusted for multiple comparisons using the Bonferroni correction method.

\section{RESULTS}

\section{Descriptive characteristics}

Out of 30 participants enrolled, 4 had a change in health status and were non-ambulatory at follow-up, 3 had no questionnaire scores at the initial assessment and 2 had no follow-up (one deceased, one lost to follow-up). Data analysis for this study involved 21 people who were on average $61.6 \pm 8.2$ years of age, $57 \%$ were male $(n=12), 76 \%(n=16)$ had a transtibial level amputation, and the most common amputation etiology was diabetes $62 \%(n=13)$. (Table 1)

\section{Objective mobility}

Gait velocity significantly increased for both single-task (discharge: $52.5 \pm 26.5 \mathrm{~cm} / \mathrm{s}$, follow-up: $69.6 \pm 26.1 \mathrm{~cm} / \mathrm{s} ; \mathrm{p}<0.001$ ) and dual-task (discharge: $42.3 \pm 24.0 \mathrm{~cm} / \mathrm{s}$, follow-up: $59.6 \pm 28.7 \mathrm{~cm} / \mathrm{s} ; \mathrm{p}<0.001$ ) conditions. (Figure 1) 
L Test performance significantly improved for the single-task (discharge: $79.2 \pm 51.5$ seconds, follow-up: $55.0 \pm 39.7$ seconds; $\mathrm{p}=0.002$ ), but not for the dual-task (discharge: $100.1 \pm$ 75.1 seconds, follow-up: $63.6 \pm 44.1$ seconds; $\mathrm{p}>0.003$ ) condition. (Figure 2)

\section{Subjective mobility}

None of the 14 PEQ questions demonstrated a statistically significant change between discharge and the 4-months follow-up ( $\mathrm{p}>0.003)$. (Table 2).

\section{Relationship between subjective and objective measures of mobility}

At discharge, there were no statistically significant correlations between the subjective and objective measures of mobility ( $p>0.003$ ). At follow-up, a statistically significant correlation was observed between the subjective question, "Ability to walk on the sidewalk with a prosthesis", and the L Test (ST: $\mathrm{p}<0.001, \mathrm{r}=-0.77$; DT: $\mathrm{p}<0.001, \mathrm{r}=-0.77$ ).

\section{DISCUSSION}

The present study demonstrated that gait velocity and L Test performance substantially improved between discharge and 4-months follow-up. Yet, no subjective reports of mobility completed by participants changed over the same time frame. Additionally, our study found little evidence of a relationship between the tests of objective mobility and self-reported subjective mobility after rehabilitation in PLLA.

The gait velocity observed at discharge from inpatient rehabilitation is comparable to previous PLLA literature. ${ }^{19}$ However, at both time points gait was substantially slower than what is observed in PLLA experienced with prosthesis walking ${ }^{20}$ or community-dwelling older adults $^{21}$. The change in L Test single-task and dual-task performance was well above the minimum detectable change $\mathrm{e}^{7,16}$ and is considered clinically relevant ${ }^{22}$. Similar L Test performance early in PLLA rehabilitation has been previously observed. ${ }^{23}$ Inpatient prosthetic 
rehabilitation is the first step for PLLA, and it is expected that individuals will improve as they become more experienced with their prosthetic device.

Despite improvements in functional outcomes, participants in this study did not rate their subjective walking ability to be different between discharge and 4-months follow-up. Previous research by Roepke et al. ${ }^{24}$ demonstrated that for individuals with dysvascular lower limb amputation, social participation is influenced by physical factors, but satisfaction with mobility is influenced by psychosocial factors. The lack of perceived change in walking abilities may reflect a mismatch between expectations of outcomes and realized outcomes, or that self-reported scoring criteria of one's own ability changes over time. Evidence of goal resetting as performance improves has been previously elucidated in sport psychology. ${ }^{25}$ If baseline expectations used to assess self-perception of abilities changes with rehabilitation, individuals may report their abilities to be the same even when large performance improvements are observed.

Only one of the fourteen subjective mobility questions correlated with objective mobility, which was observed at follow-up but not at discharge. Similar results in other clinical populations such as in stroke patients have been reported. ${ }^{12,26}$ Although substantial improvements in usual and fast walking velocities were observed after an exercise intervention in the people with stroke, participants did not report a subjective gain in their abilities. ${ }^{12}$ Importantly, research has demonstrated that older adults are able to perceive when changes in physical function occur due to participation is an exercise program. ${ }^{27}$

Several recommendations can be made based on the results of this study. Obtaining both objective and subjective measures, rather than individual measures alone, may allow for a more accurate representation of an individual's abilities in this population. Additionally, and based on 
results from the current study, inferring objective ability from subjective scores, or vice versa, may not be appropriate in PLLA. Future research should further investigate the factors that influence subjective mobility in PLLA such as level of amputation, balance confidence and socket fit/comfort. Furthermore, future research should include a more in-depth analysis of various subjective and objective tests and potential confounders in this population.

There are a number of limitations to the current study. Six individuals were unable to complete follow-up testing. This highlights the difficulty of completing longitudinal research in this population as patients experience continued limitations in mobility. On average, the study sample were middle-aged adults with a below knee amputation of diabetic etiology. Our study results may underestimate the typical rehabilitation progress of PLLA with a traumatic etiology. However, all participants that were eligible during the specified time frame were recruited. Therefore, our sample is an accurate representation of the individuals participating in inpatient prosthetic rehabilitation at this centre.

\section{CONCLUSIONS}

People with a first unilateral transtibial or transfemoral level lower limb amputation were able to make substantial gains on measures of objective mobility between discharge and 4-months following inpatient prosthetic rehabilitation. However, our study participants did not have a change in subjective walking ability in the same time frame. Additionally, and unexpectedly, there was no relationship between the types of mobility measures at the different time points. Therefore, both subjective and objective measures of mobility should be evaluated in all PLLA patients as each provides different and valuable information to clinicians.

\section{ACKNOWLEDGMENTS}

None. 


\section{REFERENCES}

1. American Academy of Orthotists and Prosthetists. Post-Operative Management of the Lower Extremity Amputee: Official Findings of the Consensus Conference. Vol 16.; 2004.

2. Fortington L V., Dijkstra PU, Bosmans JC, Post WJ, Geertzen JHB. Change in healthrelated quality of life in the first 18 months after lower limb amputation: A prospective, longitudinal study. J Rehabil Med. 2013;45(6):587-594.

3. Davie-Smith F, Coulter E, Kennon B, Wyke S, Paul L. Factors influencing quality of life following lower limb amputation for peripheral arterial occlusive disease: A systematic review of the literature. Prosthet Orthot Int. 2017;41(6):537-547.

4. Hart-Hughes S, Latlief GA, Phillips S, Groer S, Highsmith MJ. A review of clinical outcome assessment instruments for gait, balance, and fall risk in persons with lower extremity amputation. Top Geriatr Rehabil. 2014;30(1):70-76.

5. McIsaac TL, Lamberg EM, Muratori LM. Building a framework for a dual task taxonomy. Biomed Res Int. 2015;2015:591475.

6. Woollacott M, Shumway-Cook A. Attention and the control of posture and gait: A review of an emerging area of research. Gait Posture. 2002;16(1):1-14.

7. Hunter SW, Frengopoulos C, Holmes J, Viana R, Payne MW. Determining reliability of a dual-task functional mobility protocol for individuals with lower extremity amputation. Arch Phys Med Rehabil. 2018;99(4):707-712.

8. Pell JP, Donnan PT, Fowkes FGR, Ruckley C V. Quality of life following lower limb amputation for peripheral arterial disease. Eur J Vasc Surg. 1993;7(4):448-451.

9. Miller WC, Deathe AB, Speechley M. Lower extremity prosthetic mobility: A comparison of 3 self-report scales. Arch Phys Med Rehabil. 2001;82(10):1432-1440. 
10. Draicchio F, Tatarelli A, Castellano S, et al. Comparative analysis of the assessment methods of the rehabilitative-prosthetic path of the patient with lower limb prosthesis. Adv Intell Syst Comput. 2020;970:443-457.

11. Schaffalitzky E, Gallagher P, Maclachlan M, Ryall N. Understanding the benefits of prosthetic prescription: Exploring the experiences of practitioners and lower limb prosthetic users. Disabil Rehabil. 2011;33(15-16):1314-1323.

12. Tang A, Eng JJ, Rand D. Relationship between perceived and measured changes in walking after stroke. J Neurol Phys Ther. 2012;36(3):115-121.

13. von Elm E, Altman DG, Egger M, Pocock SJ, Gøtzsche PC, Vandenbroucke JP. The Strengthening the Reporting of Observational Studies in Epidemiology (STROBE) statement: guidelines for reporting observational studies. J Clin Epidemiol. 2008;61(4):344-349.

14. Powell LE, Myers AM. The Activities-specific Balance Confidence (ABC) Scale. Journals Gerontol Ser A Biol Sci Med Sci. 1995;50A(1):M28-M34.

15. Nasreddine ZS, Phillips NA, Bédirian V, et al. The Montreal Cognitive Assessment, MoCA: A brief screening tool for mild cognitive impairment. J Am Geriatr Soc. 2005;53(4):695-699.

16. Deathe AB, Miller WC. The L Test of Functional Mobility: Measurement properties of a modified version of the Timed "Up \& Go" Test designed for people with lower-limb amputations. Phys Ther. 2005;85(7):626-635.

17. Legro MWM, Reiber GDG, Smith DGD, et al. Prosthesis evaluation questionnaire for persons with lower limb amputations: Assessing prosthesis-related quality of life. Arch Phys Med Rehabil. 1998;79(8):931-938. 
18. Muir-Hunter SW, Montero-Odasso M. The attentional demands of ambulating with an assistive device in older adults with Alzheimer's disease. Gait Posture. 2017;54(3):202208.

19. Batten HR, McPhail SM, Mandrusiak AM, Varghese PN, Kuys SS. Gait speed as an indicator of prosthetic walking potential following lower limb amputation. Prosthet Orthot Int. 2019;43(2):196-203.

20. Lin S-J, Winston KD, Mitchell J, Girlinghouse J, Crochet K. Physical activity, functional capacity, and step variability during walking in people with lower-limb amputation. Gait Posture. 2014;40(1):140-144.

21. Hollman JH, McDade EM, Petersen RC. Normative spatiotemporal gait parameters in older adults. Gait Posture. 2011;34(1):111-118.

22. Rushton PW, Miller WC, Deathe AB. Minimal clinically important difference of the L Test for individuals with lower limb amputation: A pilot study. Prosthet Orthot Int. 2015;39(6):470-476.

23. Miller WC, Deathe AB. The influence of balance confidence on social activity after discharge from prosthetic rehabilitation for first lower limb amputation. Prosthet Orthot Int. 2011;35(4):379-385.

24. Roepke AM, Williams RM, Turner AP, et al. A Longitudinal study of social participation after dysvascular lower extremity amputation. Am J Phys Med Rehabil. 2017;96(10):741747.

25. Kyllo LB, Landers DM. Goal setting in sport and exercise : A research synthesis to resolve the controversy. J Sport Exerc Psychol. 1995;(1981):117-137.

26. Robinson CA, Shumway-Cook A, Ciol MA, Kartin D. Participation in community 
walking following stroke: Subjective versus objective measures and the impact of personal factors. Phys Ther. 2011;91(12):1865-1876.

27. Emery CF, Blumenthal JA. Perceived change among participants in an exercise program for older adults. Gerontologist. 1990;30(4):516-521. 
Table 1: Demographics and clinical characteristics of a sample of people with a lower limb amputation.

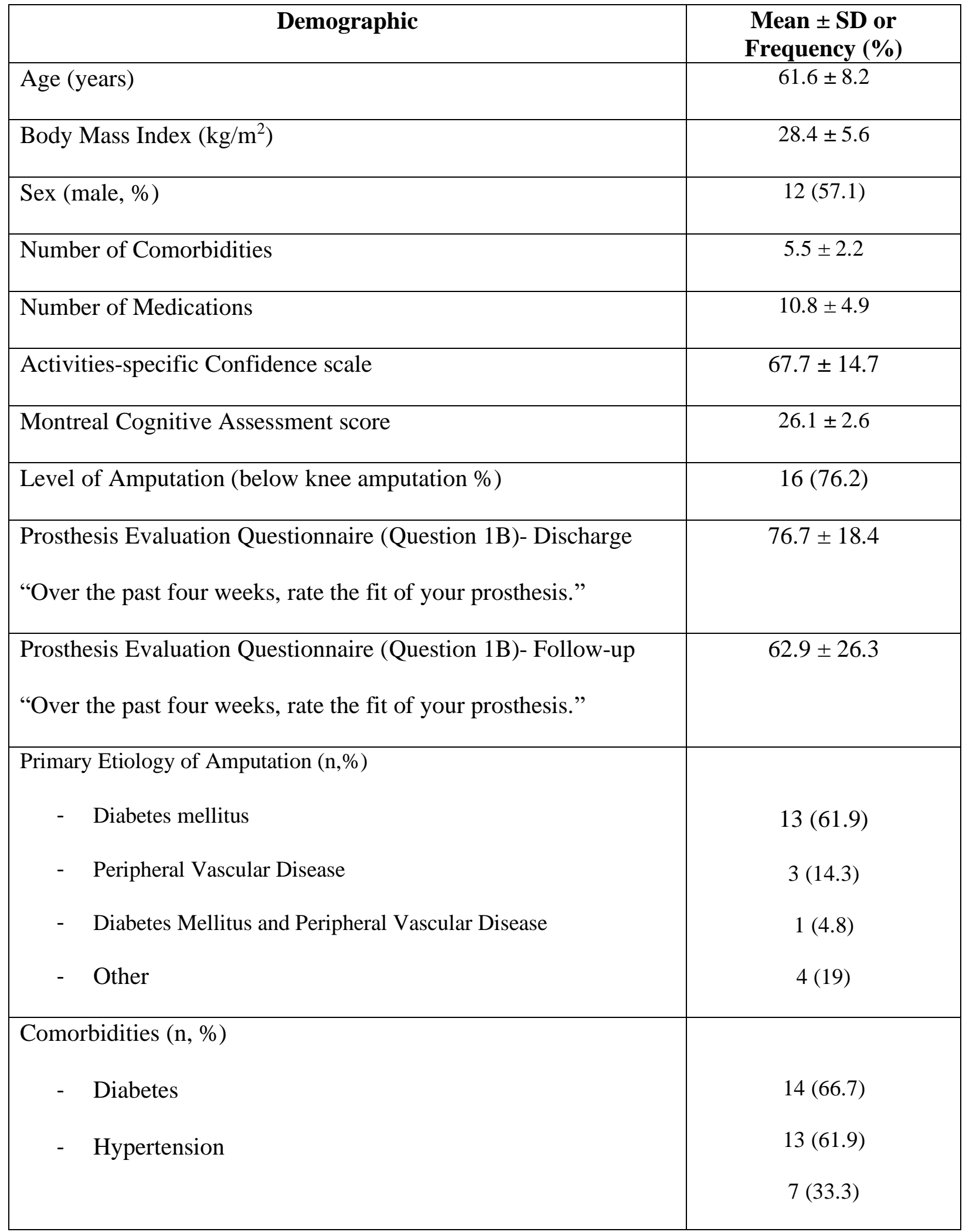




\begin{tabular}{|l|c|}
\hline - Angioplasty & $3(14.3)$ \\
- Myocardial infarction & $7(33.3)$ \\
- Osteoarthritis & $1(4.8)$ \\
- Transient Ischemic Attack & \\
\hline
\end{tabular}


Table 2: Average scores of subjective and objective measures of mobility at discharge from rehabilitation and 4-months after discharge in people with a major unilateral lower limb amputation.

\begin{tabular}{|c|c|c|c|}
\hline & \multicolumn{2}{|c|}{ Mean \pm Standard Deviation } & \multirow{2}{*}{$\begin{array}{l}\text { Paired } \\
\text { t-Test* } \\
\text { p-value }\end{array}$} \\
\hline & $\begin{array}{l}\text { Discharge from } \\
\text { Rehabilitation }\end{array}$ & $\begin{array}{l}\text { 4-Months } \\
\text { Follow-up }\end{array}$ & \\
\hline \multicolumn{4}{|l|}{$\begin{array}{l}\text { Subjective Measures of Mobility - Prosthesis Evaluation Questionnaire (Section } 4 \text { and Section 5) } \\
\text { "Over the last four weeks, rate..." }\end{array}$} \\
\hline 4.A Your ability to walk when using your prosthesis. & $81.4 \pm 17.0$ & $65.3 \pm 33.1$ & .03 \\
\hline 4.B Your ability to walk in close spaces when using your prosthesis. & $74.9 \pm 25.6$ & $65.1 \pm 31.5$ & .24 \\
\hline 4.C Your ability to walk upstairs when using your prosthesis. & $79.5 \pm 21.0$ & $65.5 \pm 38.2$ & .12 \\
\hline 4.D How you have felt about being able to walk down stairs when using your prosthesis. & $80.2 \pm 21.1$ & $70.3 \pm 36.4$ & .22 \\
\hline 4.E Your ability to walk up to a steep hill when using your prosthesis. & $56.8 \pm 35.0$ & $46.2 \pm 31.5$ & .29 \\
\hline 4.F Your ability to walk down a steep hill when using your prosthesis. & $56.0 \pm 34.2$ & $43.9 \pm 32.5$ & .18 \\
\hline 4.G Your ability to walk on sidewalks and streets when using your prosthesis. & $79.7 \pm 29.2$ & $76.7 \pm 30.9$ & 69 \\
\hline $\begin{array}{l}\text { 4.H Your ability to walk on slippery surfaces (e.g. wet tile, snow, a rainy street, or a boat deck) } \\
\text { when using your prosthesis. }\end{array}$ & $44.9 \pm 30.8$ & $54.1 \pm 35.3$ & .47 \\
\hline
\end{tabular}




\begin{tabular}{|c|c|c|c|}
\hline 4.I Your ability to get in and out of a car when using your prosthesis. & $85.2 \pm 19.4$ & $91.0 \pm 9.4$ & .17 \\
\hline $\begin{array}{l}\text { 4.J Your ability to sit down and get up from a chair with a high seat (e.g., a dining chair, a } \\
\text { kitchen chair, an office chair). }\end{array}$ & $93.9 \pm 9.4$ & $87.0 \pm 21.8$ & .11 \\
\hline $\begin{array}{l}\text { 4.K Your ability to sit down and get up from a low or soft chair (e.g., an easy chair or deep } \\
\text { sofa). }\end{array}$ & $72.0 \pm 26.7$ & $59.3 \pm 33.3$ & .03 \\
\hline 4.L Your ability to sit down and get up from the toilet. & $91.5 \pm 11.5$ & $87.6 \pm 24.2$ & .47 \\
\hline 4.M Your ability to shower or bathe safely. & $84.6 \pm 21.5$ & $90.0 \pm 13.6$ & .34 \\
\hline 5.B How satisfied you have been with how you are walking. & $87.1 \pm 13.0$ & $70.2 \pm 33.7$ & .03 \\
\hline \multicolumn{4}{|l|}{ Objective Measures of Mobility } \\
\hline Gait velocity single-task $(\mathrm{cm} / \mathrm{s})(\mathrm{n}=19)$ & $52.5 \pm 26.5$ & $69.6 \pm 26.1$ & $<.001$ \\
\hline Gait velocity dual-task $(\mathrm{cm} / \mathrm{s})(\mathrm{n}=19)$ & $42.3 \pm 24.0$ & $59.6 \pm 28.7$ & $<.001$ \\
\hline L Test single-task $(\mathrm{s})(\mathrm{n}=20)$ & $79.2 \pm 51.5$ & $55.0 \pm 39.7$ & .002 \\
\hline L Test dual-task (s) $(\mathrm{n}=20)$ & $100.1 \pm 75.1$ & $63.6 \pm 44.1$ & .005 \\
\hline
\end{tabular}

Note: ${ }^{*}$, Statistical significance set as $\mathrm{p}<0.003$ to adjust for multiple comparisons. 


\section{Figure Legend}

Figure 1: Changes in gait velocity (single-task and dual-task tests) between discharge from rehabilitation and 4-months follow-up for people with unilateral lower limb amputation. * Indicates statistically significant difference $\mathrm{p}<0.003$.

Figure 2: Changes in time to complete the L Test (single-task and dual-task tests) between discharge from rehabilitation and 4-months follow-up for people with unilateral lower limb amputation. * Indicates statistically significant difference $\mathrm{p}<0.003$. 
Figure 1.

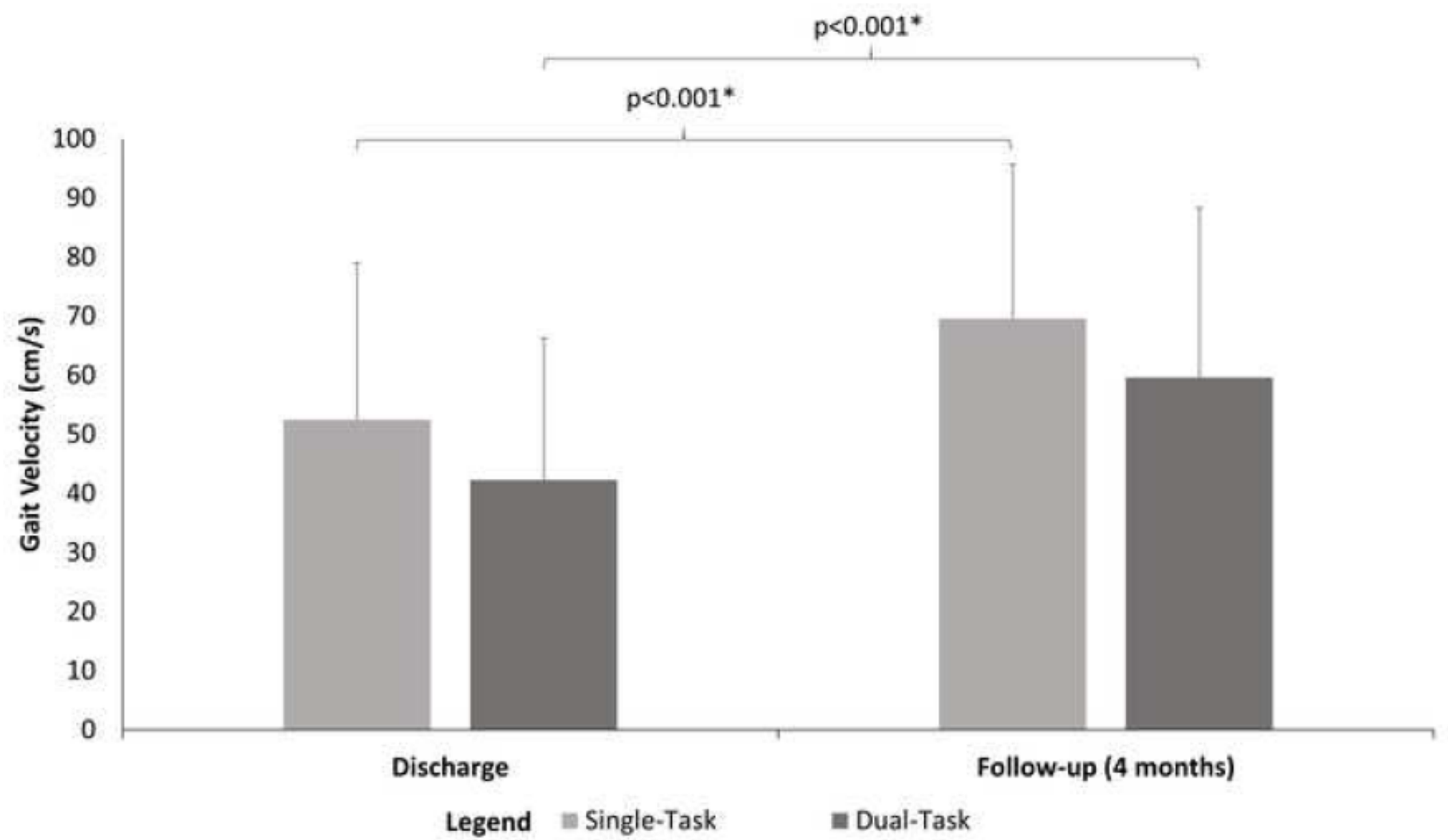


Figure 2.

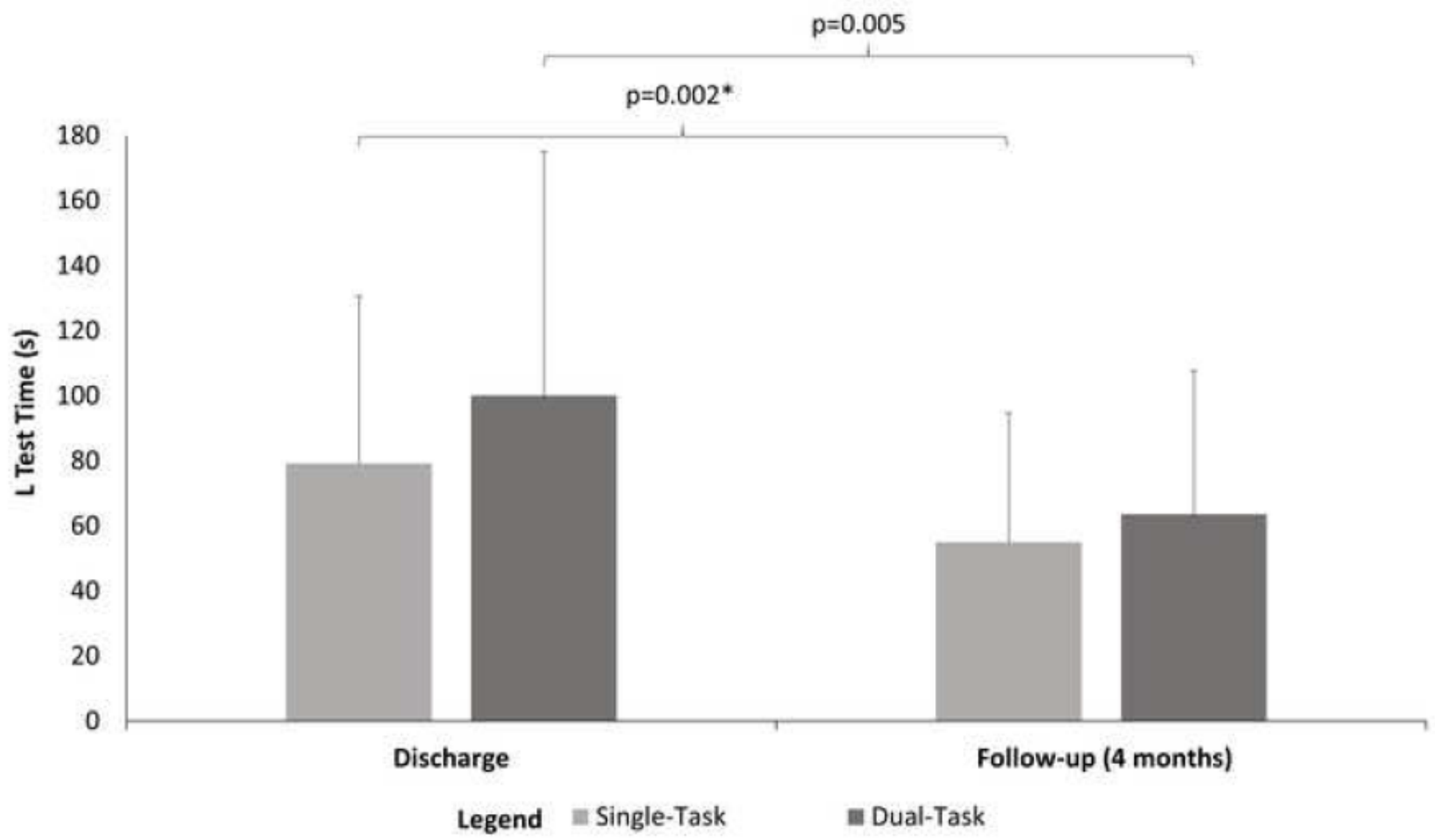

